International Journal of Child, Youth and Family Studies (2012) 1: 112-123

\title{
INTERPERSONAL RELATIONSHIPS AND DEPRESSION AMONG ADOLESCENTS LIVING IN TEHRAN'S SHELTERS
}

\author{
Katayoon Ahangar, Mariani Mansor, and Rumaya Juhari
}

\begin{abstract}
This report explores the connection between interpersonal relationships and depression among adolescents living in Tehran's shelters. A total 103 Iranian adolescents from nine governmental shelters in Tehran, comprising 69 males and 34 females between the ages of 13 and 15 years, were included in this research. A correlational design was employed in this study and a convenience sampling method was used to select respondents. The results revealed significant negative correlations for depression and difficulties with interpersonal relationships with roommates, classmates, social workers, and guardians. The results of this study will help guardians, social workers, and psychologists to organize intervention programmes that assist with relationship formation as a means for reducing depression among adolescents in Tehran's youth shelters.
\end{abstract}

Keywords: interpersonal relationship, depression, shelter, adolescent, Beck’s Depression Inventory (BDI)

Katayoon Ahangar is a Ph.D. candidate in Developmental Psychology, the Faculty of Human Ecology at Putra University, Malaysia.

E-mail: info@katayoonahangar.com

Mariani Mansor, Ph.D. is a Senior Lecturer in the Department of Human Development and Family Studies, Faculty of Human Ecology at Putra University. E-mail: mariani@putra.upm.edu.my

Rumaya Juhari, Ph.D. is an Associate Professor and Head of Department, Department of Human Development and Family Studies, Faculty of Human Ecology at Putra University. E-mail: rumaya@putra.upm.edu.my

Depression is one of Iran's most controversial clinical and general mental health issues, with approximately $2 \%$ of adolescents before maturity age and about $5 \%$ to $8 \%$ of adolescents reporting depression in this country (Navabi Nejad, 2000). According to the Iran Health Institution, the country has 28 million adolescents, and out of this total, two million of them are suffering from depression (Navabi Nejad, 2000). Among those who are experiencing depression, adolescents who live in shelters constitute a particularly vulnerable group.

According to Alvand (2008), Iranian adolescents who are living in shelters are there for a number of reasons: Three percent (3\%) of these adolescents do not have 
parents, $21 \%$ have parents who are unable to look after them, $16 \%$ have divorced parents, $9 \%$ have parents in prison, and another $9 \%$ have abusive parents. These young people are almost isolated from the society and their relationships are limited to the five groups of people surrounding them including their classmates, roommates, guardians, social workers, and psychologists. These groups, which in the absence of parents and other family members play a dominant role in the lives of adolescents who live in shelters, are central to our understanding of these adolescents. It is therefore important to understand the relationships between shelter-based adolescents and members of the above-mentioned groups to better understand their effects on adolescents’ depression (Bayat, Naderi Far, Bayat, Miri, \& Saeed, 2005).

Adolescents who live in shelters are not only experiencing the whole spectrum of affective disorders, but are also suffering from serious mental illness (Sung, Jeffery, \& Kirchner, 2000). According to Sung et al., childhood depression, just like depression in adults, can involve symptoms ranging from normal responses of sadness and displeasure to stressful events, to severe harm caused by clinical depression that may or may not include evidence of mania. Important reasons for the increased incidence of depression for adolescents living in shelters are the many deprivations associated with shelter life, for example environmental and community degradation surrounding the shelters, lack of privacy, excessive structure, routine and limited autonomy, as well as other factors like past trauma related to abuse and neglect, experiences with violence, grief and loss, and so forth (Bassuk \& Weinreb, 1994; Berne, Dato, Mason, \& Rafferty, 1990; Huang \& Menke, 2001). These adolescents should be given particular attention or cared for more carefully, while psychologists, guardians, social workers, educators, and social service agencies who work with this population need to be informed about their particular needs (Masten, Miliotis, Graham-Bermann, Ramirez, \& Neemann, 1993). Therefore, in view of the statements above, this research was carried out to identify depression among adolescents living in shelters in Iran and to discover how the relationships in which these young people are involved play a role in their depression. The research was undertaken with the following research questions in mind:

1. Are there any differences in depression among male and female adolescents living in Tehran's shelters?

2. To what extent does interpersonal relationship correlate with depression among adolescents in Tehran's shelters?

\section{Objective}

- To examine the differences in depression among male and female adolescents living in shelters in Tehran.

- To examine the correlation between interpersonal relationships (namely the relationships with classmates, roommates, psychologists, social workers, and guardians) and depression among these adolescents.

\section{Depression in Shelters}

Zima, Wells, and Freeman (1994) studied emotional problems such as depression and poor school performance among sheltered children in Los Angeles. 
The objective of their study was to identify children suffering from these problems and determine the relationship between emotional problems and the use of physical and mental health services among 169 school-aged children in Los Angeles. For this purpose, interviewers used standard measures of depression and behavioural problems to assess the respondents' answers. The majority (78\%) of the children were found to be suffering from depression, were having behavioural problems, or exhibiting poor school performance. Only one-third of their parents were aware of these problems, and only $15 \%$ of the youth had ever received any mental or physical health care.

Depression among sheltered children was also studied by Wagner and Menke (1991). In their study, 51\% of sheltered children between the ages of 7 and 12 years were found to have required mental health care for depression. Of these, 35\% obtained scores that indicated clinical depression or were similar to the scores obtained by a sample of children receiving treatment for depression.

Navabi Nejad (2000) reported that most adolescents living in shelters in Iran have poor performance or poor achievement in schools. In addition, they were found to have physical, emotional, as well as social and behavioural problems as compared to adolescents living with families, and most of them have also reported maladaptive behaviour. In particular, these adolescents were found to be more sensitive, depressed, became angry very quickly, and did not care about being approved of by other people in their society. Other symptoms of depression included changes in appetite or energy, as well as sleeping much more or much less than usual (O'Connor, 2003). Further, Sayad Poor (1993) has shown that the experiences of adolescents living in shelters could strongly affect their adulthood personality and their future life. Sayad Poor also found that adolescents living in shelters are vulnerable to loneliness, depression, low self-esteem, and drug abuse, indicating that there are problems in both the functioning of sheltered adolescents and the services delivered or provided to them. Given the prevalence of mental health and other problems among youth in shelters, research on what can be done to assist them is sorely needed everywhere, but especially in Iran where little such research presently exists.

\section{Theoretical Framework}

This study was based on the human ecological systems theory proposed by Bronfenbrenner (2005). In this theory, an individual is placed at the centre of five different systems - the microsystem, mesosystem, exosystem, macrosystem, and chronosystem - and these different levels have bi-directional influences on one another. Ecological systems theory is an approach to the study of the developing human being that emphasizes the interactions and activities among the abovementioned systems, comprehensively expresses the way the people live, and talks about bi-directional effects of people and their environment on each other (Matlin, 2008).

The microsystem is the closest layer to the child and includes the daily relational interactions experienced by an adolescent. For shelter-based youth, these experiences are mostly relationships with other adolescents or with guardians, psychologists, and social workers attached to the shelter. The correlations between the elements of this system are bi-directional, both toward and away from the adolescents. 
The mesosystem consists of the immediate community and provides the connection between the structures of the child's microsystem, for example the connection between the adolescent's teacher in school and their guardians in the shelter, and so forth.

The exosystem consists of the institutional community and includes both formal and informal environments. The welfare services in shelters for adolescents are categorized as the formal environment and the guardians' social network as the informal environment.

The macrosystem is the outer layer of Bronfenbrenner's (2005) structure. It consists of the social and political community and contains a range of influences, such as a shelter's regulations, cultural issues, customs, and resources. Within the macrosystem, the chronosystem is related to an adolescent's environment and it includes the time dimension. Elements of the chronosystem are divided into two categories: internal elements such as physiological changes that happen while an adolescent gets older, and external elements like the time at which an orphaned adolescent's parents died. Adolescents may show different reactions to changes in their environment while they grow up and will be able to identify the influence of these changes on them.

In the present study the main focus is on microsystem - the immediate relationships in which the adolescents are participating. Adolescents living in shelters are most immediately connected to their classmates, roommates, psychologists, social workers, and guardians; these are shelter-based adolescents' intimate groups. It is therefore thought that each negative or positive relationship has the potential to have a long-standing effect on the self-confidence and level of mental health of these young people. Positive relationships with members of the intimate group will likely help to protect against depression while a negative relationship is likely to increase the risk for depression (Berk, 2007).

Ecological theory also notes that there might be environmental factors that protect the adolescent from being depressed. Adolescents living in various shelters in Iran, particularly those who are at the risk of increasing depression, often experience many challenges in their interactions with their classmates, roommates, guardians, psychologists, and social workers. At the same time, the ecological theory addresses these variables and recommends a way for researchers to analyze the importance of these variables and determine whether there are environmental variables that increase the possibility of developing depression.

\section{Definition}

Operationally, the term “depression” refers to feelings of sadness, guilt, worthlessness, past failure, self-dislike, suicidal thoughts, loss of pleasure, crying, loss of interest, tiredness, change of appetite, loss of interest in sexual activity, change in sleep, loss of energy, and low self-esteem. All these terms were measured in this study by responses to the Beck's Depression Inventory or BDI (Beck, Ward, Mendelson, Mock, \& Erbaugh, 1961). According to this definition adopted in the current study, levels of depression may be normal, mild, moderate, borderline, severe, and extreme. Total Score Levels of Depression were: (1-10) where these ups and 
downs are considered as normal; (11-16) mild mood disturbance; (17-20) borderline clinical depression; (21-30) moderate depression; (31-40) severe depression; and (40+) extreme depression.

Operationally, interpersonal relationship is measured based on the relationships with classmates, roommates, psychologists, social workers, and guardians with the use of a questionnaire. The Interpersonal Relationship Inventory was developed by the author with the assistance of Professor Asgari in Iran. The interpersonal relationship questionnaires had to be adapted according to the interpersonal relationships of adolescents living in shelters in Tehran. The inventory contains 60 items including 5 sub-scales (namely the relationship with classmates, roommates, psychologists, social workers, guardians) and each sub-scale has 12 items. The score for each sub-scale was 12-48. The total score for each sub-scale was divided into two categories (below the mean score was considered poor and above this mean value was considered good).

\section{Method}

\section{Participants and Procedure}

The sample consisted of 103 adolescents living in Tehran's governmental shelters. Each governmental shelter in Tehran is responsible for 20 to 25 adolescents from infancy up to age 18. The sample included 34 females and 69 males. Out of 41 governmental shelters in Tehran, only nine shelters are meant for adolescents between the ages of 13 and 15 years, and thus, the convenience sampling technique was employed for this research.

The Interpersonal Relationship Inventory self-developed. For the convenience and comprehension of the respondents, the Persian language was used for the questionnaire, while Beck’s Depression Inventory (Beck et al., 1961) was employed. For the Iranian context, this questionnaire was translated into Persian by Associate Professor Yekke Yazdan Doost, Rezvan Talab, and Peyravi (2001) as the first stage of the procedures employed in the present study. In the second stage, a permission letter from the Welfare Organization to enter the shelters was obtained. After receiving the permission letter, the procedure for data collection was initiated. In the third stage, the Interpersonal Relationship Inventory and Beck’s Depression Inventory were administered among 103 adolescents living in the nine selected shelters in Tehran. These adolescents were purposively selected from all adolescents between the ages of 13 and 15 years in Tehran's governmental shelters. The questionnaires were distributed to these adolescents by their guardians or social workers who also assisted in the shelters. They collected the questionnaires after 30 minutes. The instruction, presented by the researcher, provided each adolescent with a brief description of the purpose of the study, procedures for filling in the questionnaire, the assurance of the confidentiality of their responses, and the right to withdraw from the study at any time.

\section{Measurement}

The Interpersonal Relationship Inventory self-developed. This inventory was employed to obtain a measure of self-reported interpersonal relationship and includes 
12 items for each sub-scale and self-rated questionnaire designed to assess the presence of interpersonal relationship among the 13- to 15-year-old adolescents. For each of the 12 items, the participants were asked to choose from four answers. The reliability coefficients of these questionnaires were found to range from .74 to .86. In this study, independent variables included five sub-scales (namely the relationships with classmates, roommates, psychologists, social workers, and guardians). These variables were measured using the self-developed Interpersonal Relationship Inventory.

As previously noted, Beck’s Depression Inventory (Beck et al., 1961) was employed in this research, translated to the Persian language by Yekke Yazdan Doost, Rezvan Talab, and Peyravi (2001). This instrument was particularly employed to obtain a measure of depression. The Beck's Depression Inventory includes 21 items and is a self-reported questionnaire designed to assess the presence of depression among adolescents. For each of the 21 items, the participants were requested to choose from four answers. The reliability coefficient of these questionnaires was found to be .89 .

\section{Data Analysis}

As mentioned above in the operational definition of Interpersonal Relationship, these instruments were divided into five sub-scales, that is, relationship with classmates, roommates, psychologists, social workers, and guardians. This study developed a self-report interpersonal relationship instrument. Items of each sub-scale were developed from three sources, namely a review of the literature, analyses of psychological tests, and the administration of the two questionnaires - the Beck's Depression Inventory and the Interpersonal Relationships Inventory - to a population of adolescents aged between 13 and 15 years living in nine selected shelters in Tehran.

The analyses were conducted to assess the psychometric properties of the interpersonal relationship. As such, two fundamental principles of measurement design, namely validity and reliability, were addressed. The collected data were analyzed in two parts; the first part was a descriptive analysis to report on the frequency, reliability, validity, and percentage of the samples, while the second part was an inferential analysis that included Pearson correlation and t-test.

The statistical package for the Social Sciences for Windows (SPSS Version 17.0 for Windows) was used to analyze the data from the two questionnaires. Meanwhile, the statistical procedures were employed to examine the reliability of the Beck's Depression Inventory, as well as the reliability and validity of the Interpersonal Relationship Inventory and each of its scales.

\section{Results}

In order to explore the correlation between interpersonal relationship and depression, Pearson's Correlation multiple regression model was used. Gender was also included in the analysis. The detailed results of the hypothesis testing are presented here. More importantly, it further explores the scientific significance or insignificance in the mean differences for the categorical variables set along with the 
continuous variable. The discussion includes results from previous research along with the role of interpersonal relationship on depression among adolescents.

Table 1 shows that there is no significant difference in the mean scores of depression between male and female participants $(t=-1.91, p>0.05)$. In particular, female respondents displayed higher level of depression (see Table 2).

Table 1. Results of the Independent t-test

\begin{tabular}{lllllll}
\hline & Gender & $\boldsymbol{n}$ & Mean & SD & $\boldsymbol{t}$ & \multirow{2}{*}{} \\
\hline Depression & Male & 69 & 17.01 & 13.13 & -1.91 & .06 \\
& Female & 34 & 22.02 & 11.13 & & \\
\hline \hline
\end{tabular}

$N=103$

$* p \leq 0.05, * * p \leq 0.01$

$S D=$ Standard Deviation

Table 2 shows that the relationship with classmates $r=-.252$ and $p \leq 0.01$; for relationship with roommates $r=-.317$ and $p \leq 0.01$; for relationship with psychologists $r=-.143$ and $p \leq 0.01$; for relationship with guardians $r=-.356$ and $p \leq$ 0.01; and for relationship with social workers $r=-.305$ and $p \leq 0.01$. A multiple regression analysis was conducted to evaluate how well interpersonal relationship predicted depression among adolescents living in Tehran's shelters. Using the multiple regression analysis, a significant model emerged $F(5,97)=4.53, p<.001$. Based on this model, about $19 \%$ of the variances in depression could be explained by interpersonal relationship variables.

Table 2. Pearson's Correlation matrix: Interpersonal relationship and depression

\begin{tabular}{ll}
\hline \hline Interpersonal relationship & \multicolumn{1}{c}{ Depression } \\
\hline Classmates & $-.252^{* *}$ \\
Roommates & $-.317^{* *}$ \\
Guardians & $-.356^{* *}$ \\
Psychologists & -.143 \\
Social workers & $-.305^{* *}$ \\
\hline \hline
\end{tabular}

$* p \leq .05, * * p \leq .01$

$N=103$

Percentages of depression levels were also examined. The minority of the respondents $31.1 \%$ (32) were in the normal range of depression, $14.6 \%$ (15) were in the mild range of depression, $16.5 \%$ (17) were in the borderline range of depression, $19.4 \%$ (20) were in the moderate range of depression, 9.7\% (10) were in the severe range of depression, and $8.7 \%$ (9) were in the extreme range of depression. 


\section{Discussion}

This study reports the relationship between interpersonal relationship and depression among adolescents in Tehran's shelters. Each research question is examined separately. There was significant negative relationship between level of depression and relationship with classmates, roommates, guardians, psychologists, and social workers. The results of this study show that adolescents with lower levels of interpersonal relationship have higher levels of depression. Since adolescents living in shelters and their guardians are not the same age, they cannot share a common sense of feeling; adolescents barely establish an emotional connection with their guardians, psychologists, and social workers and therefore a close relationship can hardly be established between them. Previous research studies have reported an important relationship between depression and peers. Peers play a less important role for young adolescents than for adolescents who spend more time with their peers than others (Masten, 2005).

This study shows that age is not related to depression but gender is. Also, female adolescents report a high score for depression compared to male adolescents among this population sample. However, while some research has declared that there is no clear relation between the two variables among adolescents, other research has indicated that age is significantly correlated to depression (Bryant, 2008). Analyses of age differences in behaviour functioning among adolescents living in shelters found no significant age differences between 6 and 11 years of age (Smith, 1995).

Twenge and Nolen-Hoeksema (2002) examined the relationship between age and depression among 310 children and adolescents between the ages 8 and 16 . Considering the correlation between age and gender differences and depression, boys scored a high level of depression at age 12, while girls reported an increasing score of depression from ages 12 to 16 . As with previous studies, a majority of girls reported a higher score of depression level than boys (Twenge \& Nolen-Hoeksema, 2002).

Girls often show greater symptoms of depression as a result of negative mood than boys, while in comparison to girls, boys report more symptoms of depression caused by interpersonal problems. Moreover, this study found that girls in contrast with boys show depressive symptoms by externalizing behaviours and social problems. The negative mood in girls as a symptom of depression may be characterized by self-criticism and sadness (Berg, 2001). Ron (2004) declared that adolescents who report lower rate of depressive symptoms developed mechanisms which allow them to deny their primary needs and their desire to be cared for by other people. Therefore, they felt depression less than others and also had less sympathy for others.

\section{Limitations}

The principal limitation for this study is that depression among adolescents is a very difficult issue to study given the fact that their feelings cannot be easily interpreted. Since the information concerning child or adolescent depression may not be obtained directly from observing their behaviour, this information may be a little distorted. 
In the current study, the relationships of adolescents living in shelters in Tehran are confined to their classmates, roommates, guardians, social workers, and psychologists and they often don't have the chance to communicate with adolescents outside of the shelters. This is another limitation of this study.

This research was conducted only in Tehran as the biggest city in Iran, involving a lot of immigrants from other cities who are located in suburbs with growing populations. Out of 41 governmental shelters located in Tehran, only nine shelters are responsible for adolescents between the ages of 13 and 15 years, with five meant for females and four for males. All nine shelters were included in the present research. The remaining 32 shelters are responsible for children and adolescents below 13 years of age or above 15 .

A further limitation of the present study involved the sample size of the data collected. The study involved only 103 adolescents between the ages of 13 and 15, 34 females and 69 males. Future research should have both a larger sample and a less uniform group of adolescents living in Iranian shelters. Using interpersonal relationship inventory together with a larger sample collection by future researchers may result in fewer problems. Furthermore, the unequal number of females and males employed in the current study may constitute another limitation when comparing the two groups.

Due to time constraints and the high amount of expense incurred in carrying out the research, the researcher selected only the variables that were predicted to have more effects on the level of depression among the adolescents living in shelters, that is, based on age and gender. Similarly, the convenience sampling technique was employed for the purpose of this research in Iranian society, and thus any generalization of the findings of this study to other Iranian cities or even other countries is not possible.

\section{Implications}

This research provides empirical evidence to determine the effect of psychological variables on depression among adolescents living in Tehran's shelters. In fact, it provides empirical evidence of the bilateral negative relationship between depression and interpersonal relationships. That is, those Iranian adolescents who have lower levels of interpersonal relationships have higher levels of depression. The result of this study will help guardians, social workers, and psychologists organizing intervention programs to reduce the psychological factors which cause an increase of depression. Specifically, programs that encourage adolescents to have more friends and interactions with others can help them to be less depressed and improve their interpersonal relationships. Moreover, families, especially those involved in problems like divorce, may be able to use the findings of this study to change interactions with their adolescent children. The results of this dissertation also show that there is a significant correlation between independent variables (interpersonal relationship) and level of depression. Therefore, guardians should pay attention to the fact that their behaviour with an adolescent can strongly affect them and a better relationship will result in lower levels of depression. 
The current study declared that the level of depression in females is higher than that of males and this shows that females are more sensitive. Since females compose nearly $50 \%$ of Iran's population, paying attention to their mental and emotional needs is of obvious importance. Many reasons such as the combination between biological changes and social transitions, as well as a difficult environment, exposes the females to a wide range of problems (Berg, 2001). Therefore, females are more at risk of developing depression during childhood and early adolescence (O’Donnell, 2008). As mentioned previously, females reported more symptoms of depression and therefore, paying attention to their mental and emotional needs is an essential issue and this may result in the improvement of their interpersonal relationship.

The findings of this research provides data which can be used to predict depression and therefore can help mental health policy-makers, specifically those policies designed to decrease depression among this population. The governmental bodies funding projects to control and reduce depression can also refer to these findings. Moreover, decision-makers in mental health and medical organizations can use the results of this research to establish new programs to control the factors which contribute to depression. Finally, our findings declare a correlation between interpersonal relationship and depression.

\section{Suggestions for Future Research}

Future research is recommended that uses the results of this study to expand psychosocial variables. This could facilitate the consideration of a greater variety of subjects and social factors. Interpersonal relationship was employed to address individual factors in this study and was evaluated by examining relationships with classmates, roommates, psychologists, social workers, and guardians. Expanding the range of psychosocial factors could help to narrow the factors that may cause diversity in depression. Studying the correlation between interpersonal relationships and depression among Iranian adolescents living in shelters is helpful when studying other factors related to members of this population with more serious symptoms of depression. Moreover, future studies should reconsider the relationship between depression and background profile. In this way, future researchers can achieve a better vision on the nature of the interpersonal relationships. Future research should also entail a larger sample collection and less uniform sample of adolescents in Iranian shelters. This could be accomplished through expanding the sample collection to include shelters, orphanages, institutions, etc. By broadening the number of participants in the study, researchers will be able to better generalize the results for a particular population.

\section{Conclusion}

In conclusion, this study identified one predictor of depression. However, while age and background profile were not identified as factors, gender has definitely been identified as a predicting factor for developing depression. There was a higher score of depression among female adolescents. These findings recognize interpersonal relationships as an important determinant of depression. Moreover, these results provide experimental evidence that interpersonal relationships might affect depression among Iranian adolescents living in shelters. 
Therefore, the current study has added more empirical evidence to the body of knowledge that will inform practice and guide policy-makers hoping to alleviate depression among Iranian adolescents living in various shelters in Tehran.

\section{References}

Alvand, H. R. (2008). Divorce, prison, incapable parents are various reason for adolescents living in shelter. Retrieved September 1, 2008, from http://www.shahrzadclub.com/article.aspx?id=4939

Bassuk, E. L., and Weinreb, L. (1994). The plight of homeless children. In J. Blacher (Ed.), When there's no place like home: Options for children living apart from their natural families. Baltimore, MD: Brookes.

Bayat, M., Naderi Far, M., Bayat, M., Miri, M., \& Saeed, F. (2005). Social health among adolescents between 7-11 years in shelter. Journal of Iran Nursing, 20(51), 97-104.

Beck, A. T., Ward, C. H., Mendelson, M., Mock, J., \& Erbaugh, J. (1961). An inventory for measuring depression. Archives of General Psychiatry 4(6), 561-571.

Berg, D. H. (2001). Exploring symptoms of depression in school adolescents. Kingston, ON: Queen's University.

Berk, L. E. (2007). Development through the lifespan. Boston, New York, San Francisco: Pearson, Allen \& Bacon.

Berne, A. S., Dato, C., Mason, D. J., \& Rafferty, M. (1990). A nursing model for addressing the health needs of homeless families. IMAGE: Journal of Nursing Scholarship, 22(1), 8-13.

Bronfenbrenner, U. (2005). Making human beings human: Bioecological perspectives on human development. Thousand Oaks, CA: Sage Publications, Inc.

Bryant, D. N. (2008). Psychosocial correlates of depressive symptoms among African-American children. Washington, DC: Howard University.

Huang, C. Y., \& Menke, E. M. (2001). School aged sheltered homeless children's stressors and coping behaviors. Journal of Pediatric Nursing, 16(2), 102-109.

Masten, A. S. (2005). Peer relationships and psychopathology in developmental perspective: Reflections on progress and promise. Journal of Clinical Child and Adolescent Psychology, 34(1), 87-92.

Masten, A. S., Miliotis, D., Graham-Bermann, S. A., Ramirez, M. L., \& Neemann, J. (1993). Children in homeless families: Risks to mental health and development. Journal of Conulting and Clinical Psychology, 61(2), 335-343. 
Matlin, S. L. (2008). The relationship between exposure to violence and depression: An ecological model of protective factors among African American adolescents. Dissertation Abstracts International, 69(06), December 2008. (UMI No. 3311307)

Navabi Nejad, S. (2000). Normal and abnormal behaviour. Tehran: Ebtekar Publisher, Iran.

O'Connor, R. C. (2003). Suicidal behaviour as a cry of pain: Test of a psychological model. Archives of Suicide Research, 7, 297-308.

O’Donnell, E. H. (2008). Explanatory styles, parenting, and adolescent depression. Worcester, MA: Clark University.

Ron, Y. (2004). No man is an island: The relationship between attachment styles, sense of belonging, depression and anxiety among homeless adults. The Sciences and Engineering, 65(5B), 2648.

Sayyad Poor, Z. (1993). Understanding of family among children in shelters. University of Tehran.

Smith, K. B. (1995). Homeless school age adolescent. College of Education, University of Denver.

Sung, E., Jeffery, T., \& Kirchner, D. O. (2000). Depression in children and adolescents. Retrieved September 20, 2007, from http://www.aafp.org/afp/20001115/2297.html

Twenge, J. M., \& Nolen-Hoeksema, N. (2002). Age, gender, race, socioeconomic status, and birth cohort differences on the adolescent's depression inventory: A meta-analysis. Journal of Abnormal Psychology, 111(4), 578-588.

Wagner, J., \& Menke, E. (1991). The depression of homeless children: A focus for nursing intervention. Issues in Comprehensive Pediatric Nursing, 14(1), 1729.

Yekke Yazdan Doost, R., Rezvan Talab, H., \& Peyravi, H. (2001). Association between depression and negative behaviour among heart disease patients. Iran Journal of Clinical Psychology and Psychiatry, 6(4), 38-44.

Zima B. T., Wells K. B., \& Freeman H. E. (1994). Emotional and behavioural problems and severe academic delays among sheltered homeless children in Los Angeles County. American Journal of Public Health, 84(2), 260-264. 